\title{
Cross-cultural adaptation and translation of two pain assessment tools in children and adolescents
}

\author{
Flavia Claro da Silva, ${ }^{1}$ Luiz Claudio Santos Thuler $^{2}$
}

\begin{abstract}
Objective: To translate, back-translate and cross-culturally adapt the content of the FLACC (Face, Legs, Activity, Cry, Consolability) and Faces Pain Scale-Revised (FPS-R) scales for the evaluation of pain in Brazilian young students and adolescents.

Methods: The original scales in English were translated into Brazilian Portuguese. Scales thus obtained were back translated and reviewed. Cross-cultural adaptation included the submission of the reviewed version of the scales to 12 experts to obtain data on comprehensibility, appropriateness and acceptability. A pretest was carried out in a convenience sample (20 patients and 22 health care professionals) to assess the content of the scales. The cancer patients, 7-17 years of age, were receiving care at the outpatient department or in the pediatric ward of the National Cancer Institute.

Results: After inclusion of the recommendations made by the different professionals who participated in the processes of translation, back-translation and content evaluation of the scales, pretesting showed that $90 \%$ and $100 \%$ of participants, respectively, understood the content of the scales; the mean score for comprehension ranged from 8.8 to 10.0 in a scale ranging from 1 to 10 , with higher scores indicating better understanding.
\end{abstract}

Conclusions: Both scales were found to be easily comprehensible for the evaluation of pain in Brazilian children and adolescents with cancer.

J Pediatr (Rio J). 2008;84(4):344-349: Pain assessment, pain measurement, children, adolescents, cancer, Brazilians.

\section{Introduction}

In industrialized countries, one in every 500 children develops cancer before reaching the age of $15 .{ }^{1}$ In Brazil, it is estimated that 1.34 to $3.85 \%$ of all cases of cancer occur in patients younger than $18 .^{2}$ Data collected from institutions specializing in cancer treatment ${ }^{3}$ in the developed world have shown that $70 \%$ of children suffering from oncological disorders complain of severe pain at some point. However, that pain is usually not acknowledged, and when acknowledged, it is often treated improperly, even in top treatment centers. ${ }^{4}$ Interest in pain assessment and management in pediatric patients is on the rise. The proper assessment of pain complaint allows improved diagnosis, monitoring and treatment. ${ }^{4}$

Determining the best way to assess pain in pediatric patients has been an arduous task, especially due to issues related to verbal communication and to the development of associative thinking. 5,6 The realization that pain in newborns, children and teenagers can be undertreated due to its difficult assessment has increased awareness of the need of using scales for objective pain measurement. ${ }^{6}$ According to Hicks et al., ${ }^{5}$ more than 40 texts about pain measurement in children have been published. The three types of tools most widely used in the field of pain assessment are self-report, observational and physiological assessments. However, self-report remains the gold standard in pain assessment in children and adults. ${ }^{7}$

Faces scales for the assessment of pain complaint tend to be favored by pediatric patients, caregivers and nurses as compared to other measurement tools, such as visual analog

1. Mestranda em Neurologia, Universidade Federal do Estado do Rio de Janeiro (UNIRIO), Rio de Janeiro, RJ, Brazil. Médica, Instituto Nacional de Câncer (INCA), Rio de Janeiro, RJ, Brazil.

2. Professor da Pós-Graduação em Neurologia, UNIRIO, Rio de Janeiro, RJ e Pós-Graduação em Oncologia, INCA, Rio de Janeito, RJ, Brazil.

No conflicts of interest declared concerning the publication of this article.

Suggested citation: Silva FC, Thuler LC. Cross-cultural adaptation and translation of two pain assessment tools in children and adolescents. J Pediatr (Rio J). 2008;84(4):344-349.

Manuscript received Jan 21 2008, accepted for publication May 072008.

doi:10.2223/JPED.1809 
scales. ${ }^{8}$ The Faces Scale originally consisted of seven faces, shown in an increasing scale of pain intensity. There were issues related to the analogy between the faces and the metrics (0-5 vs. $0-10)$, since it is a seven-point scale. The scale can be easily applied and does not require any unusual piece of equipment, except for photocopies of the "faces". ${ }^{9}$ Hicks et al. developed a scale consisting of six faces, with no particular expression (crying or smiling), which had a metric correlation of $0-10$ (in an increasing scale of pain); this scale is known as the Faces Pain Scale-Revised (FPS-R). ${ }^{5}$

Several behavioral scales have been produced with the goal of improving the study of pain. However, no behavior scale has shown to be superior to others. Some are too hard to be applied in the clinical practice, due to their excessive length and time-consuming nature. ${ }^{5}$ The FLACC scale (Face, Legs, Activity, Cry, Consolability $)^{10}$ was developed to reduce the obstacles associated with the use of behavioral scales. Several studies have indicated that the FLACC is easily applicable and has excellent validity when used to show changes in pain scores before and after the administration of analgesic medication. ${ }^{10}$

Merkel et al. ${ }^{11}$ analyzed 148 children under 3 years of age. The authors used the FLACC scale to assess post-operative pain in a post-anesthesia care unit. Their conclusion was that the FLACC scale is reliable and valid in quantifying pain in children who have difficulties expressing severe pain. Malvyia et al., ${ }^{12}$ on the other hand, analyzed the reliability and validity of the FLACC scale in a study with 52 children and teenagers with cognitive disorders with age between 4 and 19 years.

Since both the FPS-R and the FLACC scales have shown to be valid and reliable pain measurement tools for use with children and teenagers, and since neither scale has yet been validated for use in Brazilian patients, the present study was developed with the aim of translating, back-translating and cross-culturally adapting the content of both scales for use in Brazil.

\section{Methods}

The FPS-R and the FLACC scale for pain assessment in young students and teenagers were assessed. The study consisted of the following stages: translation and back-translation, cross-cultural adaptation and content assessment.

The translation and back-translation process comprised five stages. First, the original scale in English was translated into Brazilian Portuguese by two independent translators who are fluent in both languages. These experts were asked to use simple language with the purpose of grasping the meaning of the item rather than producing a literal translation. We reconciled discrepancies between the translations and designed a single document that was translated into English (back-translation) by another translator who was also fluent in both languages, had experience in pain control and was unaware of the previous stages of the process. Afterwards, an independent review was performed by two experts fluent in English. Following the guidelines provided by Guillemin et al., ${ }^{13}$ these translators were informed about the objective of the study and its target population and they were requested to compare the back-translated version (in English) with the original scale. The translators were told to take into consideration the concepts of semantic equivalence, the referential meaning of the terms and the words used, as well as the general meaning of each question, the answer options and the instrument instructions resulting from the translation in comparison with the original scale. It is worth noting that in this process the referential meaning must be the same in the original text as in the translated version, and there must be literal correspondence between them. ${ }^{14}$ All professionals involved in the process were requested to suggest changes and corrections in the version under analysis.

The cross-cultural adaptation and the content assessment of both scales were carried out using the experts' evaluation and the administration of a pretest to the target populations that were supposed to answer the test in the future. As pointed out by Cronbach \& Meehl, ${ }^{15}$ the content assessment must involve a verification to check if the items in the scale are representative of what is intended to be measured. The assessment of content is related to the evaluation of the instrument in order to check if it really covers the different aspects of its object. Since there is not a statistical method to assess the content of a questionnaire due to the fact that this assessment basically depends on a consensus among experts, the assessors are invited to comment each item and suggest improvements, and it is not necessary to compare the questionnaire to any other instrument. ${ }^{14,15}$ At this stage, the translated versions of both scales were presented to 12 health professionals (physicians, nurses, nursing technicians and assistants, speech therapists and biomedical scientists). These professionals were asked to read the instrument and make suggestion, explaining the reason for their suggestions, with the purpose of improving the adaptation to the Brazilian context, trying to use simple language and making the items more understandable and clearer. Some changes were done, and a version of the instrument was designed for the pretest. The pretest of the FPS-R was administered to 20 children and adolescents with cancer, whose ages ranged between 7 and 17 years old; while 22 health professionals were interviewed in order to test the FLACC scale. According to Crocker \& Algina, ${ }^{14}$ before using a questionnaire in field research, a pretest must be administered to 15 to 30 individuals, aiming at the identification of possible comprehension difficulties resulting from the administration and presentation methods, the content of the questions and the answer choices. In addition, based on the method employed by Grassi-Oliveira et al. ${ }^{16}$ in their study, a 10 -point verbal-numerical scale was used to check if the individuals could understand what was asked. According to this scale, 

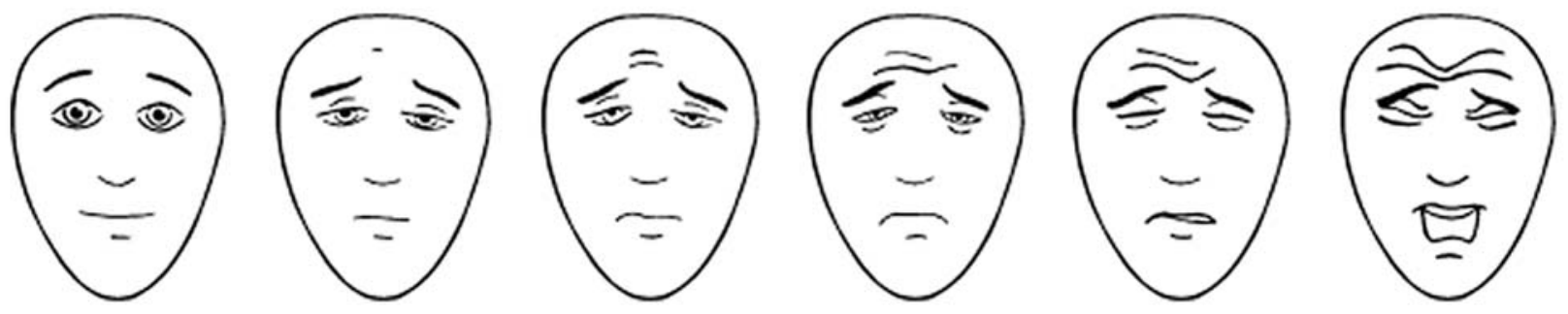

Instruções: "Essas faces mostram o quanto algo pode provocar dor. Esta face (aponte para a face mais à esquerda) não expressa dor alguma. As faces mostram cada vez mais dor (aponte para cada uma da esquerda para a direita) até esta (face mais à direita) - esta expressa muita dor. Aponte para a face que expressa quanta dor você sente (neste momento)".

Figure 1 - Final Version of the FPS-R in Portuguese

zero was the score when the individual was unable to understand anything and 10 was the score when the individual could understand everything.

The data were input into an Excel ${ }^{\circledR}$ spreadsheet. The averages for the comprehensibility variable and their respective standard deviations were calculated with the aid of the Epi-Info application (version 3.4).

This study was approved by the Research Ethics Committee of the National Cancer Institute (INCA), and all patients' caregivers or relatives signed the free and informed consent form before the beginning of the research.

\section{Results}

The final versions for the two scales translated from English to Portuguese, considering the results of the cross-cultural adaptation and content assessment, are shown in Figure 1 and Table 1.

During the translation process, some of the terms of the FPS-R were changed with the purpose of making them as understandable as possible. For instance, regarding the sentence "point to the extreme right face," instead of using the Portuguese translation apontar a face na extrema direita, we chose to use aponte para a face mais à direita, since this is more similar to the general population's way of speaking.

Regarding the FLACC scale, it was difficult to find the best translation for "consolability," since the word consolabilidade or its synonyms are hardly used in Portuguese. Also in the "face" category, one of the translators suggested the term maxilares fechados as a translation of "clenched jaw," while another translator advised us to use mandíbulas cerradas. We chose to use this last suggestion in the final version because it is more similar to the Brazilian population's way of speaking.

Another problem we found in both translated versions of the FLACC scale is related to the gender of some adjectives. Therefore, in the "activity" category, the term tenso (masculine) was changed to tensa (feminine), since we were referring to the child's activities, and child (criança) is a feminine noun in Portuguese. According to the Portuguese grammar

Table 1 - Final version of the FLACC scale in Portuguese

\begin{tabular}{|c|c|c|c|}
\hline \multirow[b]{2}{*}{ Categorias } & \multicolumn{3}{|c|}{ Pontuação } \\
\hline & 0 & 1 & 2 \\
\hline Face & $\begin{array}{c}\text { Nenhuma expressão especial ou } \\
\text { sorriso }\end{array}$ & $\begin{array}{l}\text { Caretas ou sobrancelhas } \\
\text { franzidas de vez em quando, } \\
\text { introversão, desinteresse }\end{array}$ & $\begin{array}{l}\text { Tremor freqüente do queixo, } \\
\text { mandíbulas cerradas }\end{array}$ \\
\hline Pernas & Normais ou relaxadas & Inquietas, agitadas, tensas & Chutando ou esticadas \\
\hline Atividade & $\begin{array}{l}\text { Quieta, na posição normal, } \\
\text { movendo-se facilmente }\end{array}$ & $\begin{array}{l}\text { Contorcendo-se, movendo-se } \\
\text { para frente e para trás, tensa }\end{array}$ & $\begin{array}{l}\text { Curvada, rígida ou com } \\
\text { movimentos bruscos }\end{array}$ \\
\hline Choro & $\begin{array}{l}\text { Sem choro (acordada ou } \\
\text { dormindo) }\end{array}$ & $\begin{array}{c}\text { Gemidos ou choramingos; } \\
\text { queixa ocasional }\end{array}$ & $\begin{array}{l}\text { Choro continuado, grito ou } \\
\text { soluço; queixa com freqüência }\end{array}$ \\
\hline Consolabilidade & Satisfeita, relaxada & $\begin{array}{l}\text { Tranqüilizada por toques, } \\
\text { abraços ou conversas } \\
\text { ocasionais; pode ser distraída }\end{array}$ & Difícil de consolar ou confortar \\
\hline
\end{tabular}


rules, nouns and adjectives must agree in gender. This procedure was also used in the "consolability" category when the terms satisfeito and relaxado (masculine) were replaced by satisfeita and relaxada (feminine), since consolability is related to a simpler way of speaking. Also in the "legs" category, instead of using relaxado (masculine, singular), we decided to use relaxadas (feminine, plural), since "legs" is a feminine plural noun in Portuguese. After obtaining a reviewed version, which resulted from the reconciliation of both translations of the original scale from English into Portuguese, the back-translation of the reconciled version from Portuguese into English and the independent review that analyzed the disagreements between the back-translation and the original scale, the scales were evaluated by 12 health professional. The suggestions were accepted when they were considered relevant. We did not take into consideration those suggestions related to changes in the original content of the scale.

A final version of each scale was then designed to be used in the pretest, which included its administration to future users: 20 school-aged children and adolescents with cancer aged between 7 and 17 years old (FPS-R) and 22 health professionals (FLACC scale). The participants of both groups were randomly selected.

Of the 20 participants who were evaluated using the FPS-R, 18 (90\%) declared they understood the questions, and two participants $(10 \%)$ did not understand anything. The mean score for comprehension of the FPS-R (from 0 to 10) was $8.8( \pm 2.5)$. This score reached 9.4 when the child reported she/he could understand the scale and dropped to 2.5 when the child reported she/he could not understand the scale. Some patients, besides answering the questions about their comprehension of the FPS-R, also checked off the face showing the pain they were feeling at that moment.

Among the 22 health professionals who took the pretest of the FLACC scale, the mean score for comprehension of the scale (from 0 to 10$)$ was $9.6( \pm 1.0)$ for "face," $9.9( \pm 0.4)$ for "legs," 10.0 ( \pm 0.0$)$ for "activity," $9.7( \pm 0.8)$ for "cry" and 10.0 $( \pm 0.2)$ for "consolability." All professionals (100\%) reported they could understand the scale, but eight of them made comments about its content. One of them pointed out that the difference between "occasional complaint" (queixa ocasional) and "frequent complaint" (queixa com freqüência) was not clear in the "cry" category, while another professional highlighted the subjectivity of the phrase "occasional complaint." The similarity between scores 0 and 1 in the "face" category was also pointed out: "no particular expression or smile" (nenhuma expressão especial ou sorriso) and "occasional grimace or frown, withdrawn, disinterested" (caretas ou sobrancelhas franzidas de vez em quando, introversão, desinteresse). Two other professional reported difficulties to assess a child's cry, since children cry for other reasons besides pain, such as cold, fear, irritability and hunger, for example. In addition, another professional highlighted that the phrase "normal position or relaxed" (pernas esticadas e relaxadas) in the "legs" category might raise doubts, since legs in a normal position need to be somewhat flexed, and the Portuguese word esticadas means stretched. Another comment regarding the "face" category pointed out that the words "withdrawn and disinterested" (introversão e desinteresse) are vague and could allow for a great variety of assumptions. On the other hand, one of the physicians who assessed the scale highlighted that the word "disinterested" (desinteresse), which is found in the "face" category, would be more closely related to the "activity" category, suggesting it could be replaced by "lack of interest." We found that these were relevant comments. However, some of them are not related to the process of evaluation of the scale; instead, they reveal doubts and suggestions regarding the original scales. Therefore, some of these suggestions were not taken into consideration because we believe that they would result in structural changes in the original scales.

\section{Discussion}

The lack of a process that provides a more appropriate assessment of the child's pain status often results in unrecognized pain, which leads to inappropriate management by the team of physicians, nurses and caregivers. ${ }^{17}$ The child who suffers from chronic pain needs to have this symptom constantly assessed always using the same instrument even before the pain management procedures are performed. However, such instrument must to be valid and reliable. ${ }^{18}$ The studies involving non-invasive instruments that take into consideration the cultural context and do not expose the participants to risks are more appropriate and reliable. ${ }^{16}$

The question that guided the present study was as follows: "What is the best method to assess the pain status of a child with cancer?" While facing this task, we became aware of the necessity of objectively and accurately measuring these patients' pain considering behavioral issues, which are often revealed through subjective manifestations of the pain status and also depend on several developmental stages, abstraction ability, pain quantification and symbolization, what frequently turns this assessment into a challenge for health professionals. ${ }^{17}$

Although the importance of pain assessment is widely acknowledged, it has not been established yet how it is possible to overcome the obstacles faced while trying to accurately assess pain, mainly when dealing with patients who are unable to self-report. In such a context, the use of observational scales becomes extremely important. ${ }^{19}$

The choice of the FPS-R and the FLACC scale was mainly due to the fact that the FPS-R is the preferential self-report method for measuring pain and the FLACC scale uses cognitive logic for pain assessment, which gave us the opportunity to compare two different types of measuring instruments. In addition, the pain intensity measurement using the FPS-R and 
the FLACC scale is simple and fast; therefore, not being very time-consuming for the health professionals responsible for administering them.

The translation and cross-cultural adaptation of assessment scales or diagnosis tools should follow the "emic-etic" paradigm. The "emic" side (from the word "phonemic") is related to viewing the phenomenon from the perspective of the context or culture in which it is inserted; "etic" (from the word "phonetic"), on the other hand, is related to generalization of the phenomena for comparisons in different cultures. ${ }^{20}$

In light of this perspective, the translation of a scale requires linguistic caution, since certain terms may have different scopes and specificities that are inherent to each language. The process of semantic assessment is also important because it becomes necessary to make sure that the instrument can be understood by all the members of the target population. ${ }^{21}$

Paixão et al. ${ }^{22}$ highlighted the importance of the translators' profile. According to their guidelines, it is important that the translation process is carried out by professionals whose native language and culture are the same as those into which the scale is being translated. It means that the optimal situation is that the translators are Brazilian citizens with advanced knowledge of English, which was the strategy used in the present study. However, we did not follow the guidelines provided by Guillemin et al. ${ }^{13}$ recommending that the number of back-translators is the same as the number of translators.

During the back-translation process, we followed the guidelines of Paixão et al., ${ }^{22}$ according to which it is desirable that the translators are familiar with the instrument, the target-population to which the scale is being adapted, as well as its dimensions. The back-translators must receive only limited explanations about the context; therefore, avoiding that they use their previous knowledge to correct occasional mistakes resulting from the initial translation process.

The content assessment is based on the analysis of the scope of a measurement instrument regarding the possible variables associated with an event, and such evaluation is performed by a panel of experts, not being necessary to compare the questionnaire that is being assessed with the other pain measurement instrument. ${ }^{14,15}$

We found that there was good acceptance of the FPS-R and the FLACC scale by children and adolescents, as well as caregivers and assessors, respectively, which, at least partially, may be due to the fact that the institution where this study was conducted has been administering the Wong-Baker Faces Pain Rating Scale to assess its patients' pain complaint.

Besides the processes of translation and back-translation and the semantic assessment, the scales were tested by their target populations (school-aged children, adolescents and health professionals) during the pilot study with the purpose of assessing their content, comprehension and acceptance.
One of the difficulties we found in this process was the low educational level of a large number of the children, which is a problem faced by other authors as well. ${ }^{22}$ The inclusion of professionals from different health areas in this process, such as psychologists, biomedical scientists, physical therapists and physicians, was considered as crucial, since it had the purpose of assuring an interdisciplinary character to the scales.

Furthermore, the appropriate comprehension of the FPS- $R$, with a mean score for comprehension of the questions of 9.4, is consistent with data from previous studies that have demonstrated children and adolescents' preference for faces scales instead of visual analogue, numerical or descriptive scales. ${ }^{23}$ We believe that the score for comprehension of the FLACC scale is also good, with mean values ranging from 9.6 to 10.0 for the comprehension of the questions in each one of the dimensions.

We conclude that this study provides the necessary foundations for continuing the validation process of both scales in Brazilian school-aged children and adolescents with cancer aiming at eliminating a gap in the correct assessment of these patients' pain status, which will result in deeper knowledge about their pain and improvement of the therapeutic proposals.

\section{Acknowledgements}

To all the patients and staff members from the National Cancer Institute who took part in this study.

\section{References}

1. Clavel J. Epidemiology of childhood cancers. Rev Prat. 2007;57: 1061-9.

2. Reis RS, Santos MO, Thuler LC. Incidência de tumores pediátricos: análise das informações de 17 Registros de Base Populacional no Brasil. Rev Bras Cancerol. 2002;53:5-15.

3. Chun DY, Turner JA, Romano JM. Children of chronic pain patients: risk factors for maladjustment. Pain. 1993;52:311-7.

4. World Health Organization (WHO). International Association of Pain. Cancer pain relief and palliative care in children. Geneva: World Health Organization; 1998.

5. Hicks, CL, Von Baeyer CL, Spafford PA, Van Korlaar I, Goodenough B. The Faces Pain Scale-Revised: toward a common metric in pediatric pain measurement. Pain. 2001;93:173-83.

6. Grégoire MC, Finley AG. "Doctor, I think my baby is in pain": the assessment of infants' pain by health professionals. J Pediatr (Rio J). $2008 ; 84: 6-8$.

7. Voepel-Lewis T, Malviya S, Tait AR. Validity of parent ratings as proxy measures of pain in children with cognitive impairment. Pain Manag Nurs. 2005;6:168-74.

8. Keck JF, Gerkensmeyer JE, Joyce BA, Schade JG. Reliability and validity of the Faces and Word Descriptor Scales to measure procedural pain. J Pediatr Nurs. 1996;11:368-74. 
9. Bieri D, Reeve RA, Champion GD, Addicoat L, Ziegler JB. The Faces Pain Scale for the self-assessment of the severity of pain experienced by children: development, initial validation and preliminary investigation for ratio scale properties. Pain. 1990; 41:139-50.

10. Willis MH, Merkel SI, Voepel-Lewis T, Malviya S. FLACC Behavioral Pain Assessment Scale: a comparison with the child's self-report. Pediatr Nurs. 2003;29:195-8.

11. Merkel SI, Voepel-Lewis T, Malviya S. Pain assessment in infants and young children: the FLACC scale. Am J Nurs. 2002;102: 55-8.

12. Malviya AS, Voepel-Lewis T, Merkel SI. Difficult pain assessment and lack of clinician knowledge are going barriers to effective pain management in children with cognitive impairment. Acute Pain. 2005;7:27-32.

13. Guillemin F, Bombardier C, Beaton D. Cross-cultural adaptation of health-related quality of life measures: literature review and proposed guidelines. J Clin Epidemiol. 1993;46:1417-32.

14. Crocker L, Algina J. Introduction to classical and modern test theory. New York: Holt, Rinehart and Winston; 1986.

15. Cronbach LJ, Meehl PE. Construct validity in psychological tests. Psychol Bull. 1955;52:281-302.

16. Grassi-Oliveira R, Stein LM, Pezzi JC. Tradução e validação de conteúdo da versão em português do Childhood Trauma Questionnaire. Rev Saude Publica. 2006;40:249-55.

17. Torritese $P$, Vendrúsculo DM. A dor na criança com câncer: modelos de avaliação. Rev Latino-Am Enfermagem. 1998;6: 49-55.
18. Wong DL, Baker CM. Pain in children: comparison of assessment scales. Pediatr Nurs. 1998;14:9-17.

19. Malviya S, Voepel-Lewis T, Burke C, Merkel S, Tait AR. The revised FLACC observational pain tool: improved reliability and validity for pain assessment in children with cognitive impairment. Paediatr Anaesth. 2006;16:258-65.

20. Mattos P, Segenreich D, Saboya E, Louzã M, Dias G, Romano M. Adaptação transcultural para o português da escala Adult Self-Report Scale para avaliação do transtorno de déficit de atenção/hiperatividade (TDAH) em adultos. Rev Psiquiatr Clin. 2006;33:188-94.

21. Pasquali L. Princípios de elaboração de escalas psicológicas. Rev Psiquiatr Clin. 1998;25:206-13.

22. Paixão CM Jr, Reichenheim ME, Moraes CL, Coutinho ES, Veras RP. Adaptação transcultural para o Brasil do instrumento Caregiver Abuse Screen (CASE) para detecção de violência de cuidadores contra idosos. Cad Saude Publica. 2007;23:2013-22.

23. Newman CJ, Lolekha R, Limkittikul K, Luangxay K, Chotpitayasunondh T, Chanthavanich P. A comparison of pain scales in Thai children. Arch Dis Child. 2005;90:269-70.

\section{Correspondence:}

Flávia Claro da Silva

Rua Conrado Niemeyer, 14/104 - Bloco A

CEP 22021-050 - Rio de Janeiro, RJ - Brazil

E-mail: fla_claro@hotmail.com 